\title{
Students' research activities as an element of the life safety basics school course
}

\author{
Tatiana Gordienko ${ }^{1, *}$, Yelena Svyatokho ${ }^{2}$, Larisa Ilchencko ${ }^{1}$ \\ ${ }^{1}$ Crimean Engineering and Pedagogical University the name of Fevzi Yakubov, 295015, Simferopol, \\ Russia \\ ${ }^{2}$ Ecological and biological center, 295017, Simferopol, Russia
}

\begin{abstract}
Some features of the Life Safety Basics school course, which can be used for the effective implementation of school students' research activities analyzed. To assess the teachers' attitude to the students' research activities, a questionnaire was developed. The study revealed that the main learning effects of students' research activities for the students include development: skills to work with scholarly publications and information, manage self-education process; research skills; critical and analytical thinking. A teacher as a students' research activities supervisor increases the level of students' professionalism, meets the educational standard requirements, gets the opportunity to realize the potential of each student and increase the level of their subject knowledge. Herewith, methodological problems of designing and managing students' research activities in the teaching practice are identified: students' research activities are not integrated into the everyday learning process; research methods in the classroom, as those that formed primary research skills, are used in fragments. The authors conclude that there is a contradiction between the formal teacher's understanding of students' research activities effectiveness for the meta-subject, personal and social competencies development and the non-system use. Attention is drawn to the lack of future teachers training issue development to implement research methods in teaching as a necessary professional activity element. Thus, there is a need to improve future teachers' professional training, which would include formation of the preparedness for the design and management of students' research activities in the classroom and in extracurricular activities for the Life Safety Basics school course.
\end{abstract}

\section{Introduction}

The students' research activities (SRA; the terms inquiry, inquiry-based methods, inquiry learning and teaching approaches are more commonly used in publications by Englishlanguage authors; here and after SRA will be used as equivalent - author's note) as an effective way to achieve personal and socially oriented educational results, the meta-subject competencies formation, the critical and analytical thinking development, creativity development, the ability to work with wealth of information, and productively manage the

\footnotetext{
${ }^{*}$ Corresponding author: tatgordienko@gmail.com
} 
self-education process is given a lot of attention by the scientific community [1]. Research activities aimed at the systematic scientific thinking formation, personal development activation and self-determination of students acquire special significance at the preprofessional training stage $[2,3,4]$. It should also be noted that the mandatory of an individual students' educational project or research is regulated by a number of legal documents [5].

Based on the theoretical analysis of psychological, pedagogical and methodological literature, the thematic interview results, and group discussions with the students' research activities supervisors (SRA supervisors), we believe that the Life Safety Basics school course (LSB course) has a number of features that make it highly effective for the schoolchildren research activities organization:

Regular appearance of the new types of a technogenic, informational, social, and natural character threats leads to constant updating of the discipline content [6]. On the one hand, this makes it difficult to develop a unified approach to teaching, but on the other hand, it makes possible to expand the field of research by applying not used before Computer Science, History, Economics subjects' content and their methodological approaches and methods in new perspective.

The interdisciplinary nature of the LSB course allows to target students to a broad way of knowing the surrounding reality, combining knowledge from various fields. Such meaningful integration increases the subject knowledge level, develops systematic thinking, forms students' meta-subject competencies and, according to [7], generates the holistic world view through the awareness versatility, objects interdependence and phenomena. Having emerged at the intersection of natural, technical and social sciences, the LSB course overcomes the fragmentary individual academic disciplines knowledge and gives students a comprehensive, systematic vision of the processes and phenomena studied in Biology, Geography, Physics, Chemistry, and Ecology [8].

Practical orientation, coupled with the student' life experience [9], brings the LSB course to a personalized functioning level, which helps to raise the learning motivation, build individual educational trajectories and involve students in practice-oriented, personally significant research activities.

Of the great importance for the systematic training organization based on the research approach is the teacher's understanding of its essence and their readiness to use it in teaching practice [10]. The issues of forming and developing the functional, psychological, methodological, organizational and managerial teachers' preparedness to design, organize, support and manage the SRA at different educational stages are widely covered in scientific studies $[11,12 ; 13,14]$. At the same time, the scientific periodical analysis did not indicate a significant number of publications that reveal the professional teacher training issues to accompany this type of schoolchildren cognitive activity. One of the lack comprehensive scientific research indicators in this area is the fact that from 205 SRA supervisors of the research competitions winners for the students of grades 5-11 in the Republic of Crimea in 2016-2020, only two were the Life Safety Basics course teachers (LSB teacher) (according to the final orders; https://monm.rk.gov.ru).

To concretize the program for modifying the professional training of future LSB teachers, including the practical preparedness for the design, manage and support of school students' research activities on the LSB course, it is necessary to analyze the existing practice of managing research activities, which was the purpose of the study.

\section{Methodology and methods}

A set of methods was used: 1) normative documents regulating the organization and support of schoolchildren research activities in the learning process study; 2$)^{\circ}$ psychological, pedagogical and methodological literature theoretical analysis; 3) the target group 
representatives questioning; 4) the individual teachers' experience study; 5) conducting thematic interviews and group discussions to test the assumptions made.

In order to understand the pedagogical community's current attitude to the SRA as an learning tool that can be used to achieve the goals and objectives of the Federal State Educational Standard (FSES) of Secondary General Education, the first stage analyzed the legal documents regulating the research training introduction in the practice of general educational organizations, studied the students' participation dynamics in research competitions of a natural science orientation for 2016-2020, meetings were held with teachers (SRA supervisors). Then, based on the analysis of psychological, pedagogical and methodological literature, a questionnaire of two parts was developed. The questionnaire passport part included the following questions:

1. Residence region (by municipality);

2. Gender;

3. Education;

4. Teaching experience;

5. The subject being taught.

The questionnaire main part consisted of the following questions:

1. Do you consider the students' research activities an important element of the educational process in your subject?

2. Do you have experience in organizing and supporting students' research activities in your subject?

3. Do you use research teaching methods in the classroom?

4. In your opinion, does the students' research activities organization give (can give) you as a teacher the opportunity to... (no more than three choices from the suggested options)

5. In your opinion, involving students in research activities primarily helps (can help) them to ... (no more than three choices from the suggested options)

Questionnaire makes it possible to assess the teachers' attitude to the students' research activities potential as an innovative learning technology in the framework of teaching the discipline, identify contradictions in the practice of its implementation in the educational process and offer promising ways to improve the professional and pedagogical future LSB teachers training of secondary education including the formation of preparedness to design students' research activities.

In April 2020, a teachers' remote survey in the Republic of Crimea was conducted using the Google-form. 151 people from 7 municipalities of the republic (4 city districts, $3^{\circ}$ regions) took part in the survey. The link to the questionnaire was sent to the respondents' email addresses. Teachers participated on the condition of anonymity and confidentiality. The results are presented in a generalized form.

\section{Results and discussion}

Teachers of the Republic of Crimea took part in the survey, including Biology teachers $46 \%$, LSB teachers $-28 \%$, Chemistry teachers $-24 \%$, Geography teachers $-2 \%$. The inclusion of Biology, Chemistry and Geography teachers in the survey, along with the study group of LSB teachers, is justified by the fact that these academic disciplines are most significantly close to the LSB course through stable interdisciplinary connections. We also considered that $62 \%$ of respondents teach in small rural schools, where one teacher combines teaching in several academic disciplines. Often the LSB course is taught by a teacher of Biology, Chemistry, Geography, less often Technology or Physical Education. In some municipalities, this figure may reach two-thirds of the total number of LSB teachers (according to the statistics of municipal education departments). In our survey only $40 \%$ of the total sample of LSB teachers indicated that they teach this academic discipline as a single 
subject, mostly urban school teachers. The same pattern is typical for other Russian regions [15]. Besides, the first graduation with the qualification Life Safety Basics Teacher in Republic of Crimea was only in 2020.

$79 \%$ of respondents are women. Of the group of LSB teachers, almost half are men (58\%), who is $81 \%$ of the total number of male respondents.

$60 \%$ of respondents have more than 15 years of teaching experience, and $17 \%$ of young professionals with less than 3 years of experience. The same ratio is maintained for LSB teachers.

Most of those who took part in the survey have basic pedagogical education (88\%), for the rest of the respondents, pedagogical education is additional. For LSB teachers, this figure was $74 \%$ and $26 \%$, respectively. Thus, about a quarter of LSB teachers do not have a basic pedagogical education, mostly military retirees, for whom the work of a teacher has become a new specialty.

Based on the respondents' distribution by teaching experience and the number of teachers who combine the teaching of the LSB course with other academic subjects, we can conclude that the respondents' majority received the basic pedagogical education in another subject area, and the qualification Life Safety Basics Teacher - in the process of additional professional training. Regional Institute for advanced postgraduate teacher education (https://krippo.ru) offers two retraining programs on the theory and methodology of teaching the LSB course in part-time and distance learning with duration of 360 hours each. From our point of view, this number of hours is not enough to ensure subject quality, psychological, pedagogical, methodical and practical training of LSB teacher, especially if we are talking about a full professional reorientation, which requires not only a complete update of the training content but professional skills and competencies revision, their transfer to the new subject taught [16].

Thus, we can say about the contradiction between the increasing requirements for the secondary school teacher training that is able to use innovative research training learning technologies, and the real preparedness level for the effective professional duties' performance by the teachers' majority that exists in the practice. First of all, the current situation requires close attention from the system of teachers' professional development and retraining, since it can quickly offer targeted modular courses for teachers [17, 18]. At the same time, the system of professional future LSB teachers training should also consider the fact that the number of hours allocated for studying the LSB course in general educational schools often do not allow the teacher to provide a full pedagogical workload. This is especially true for small schools located in towns or in rural areas. Therefore, we consider it appropriate to study and disseminate a number of Russian higher education institutions experience that are already training specialists in related fields: Life Safety and Biology (http://tgpi.ru), Life Safety and Additional Education Fundamentals (http://www.pgsga.ru), Physical Culture and Life Safety (https://narfu.ru). On the one hand, the spread of this practice makes it possible to strengthen fundamental subject, methodological, research, practical, psychological training in the future specialty. On the other hand, it will make the future teacher more competitive, economically protected and, possibly, reduce the outflow of young professionals from schools.

As for teachers' reflexive assessment of students' learning opportunities offered by SRA, then it is also possible to identify some methodological problems.

To the question "Do you consider the students' research activities an important element of the educational process in your subject?" the majority of respondents (85\%) gave an affirmative answer; among LSB teachers, this figure was 70\%. Despite such a high percentage of positive responses, the number of choices for the "I can't answer" option (23\% for the study group of LSB teachers) is alarming, as it may indicate that the respondents do not have a clear position on this issue. Therefore, we can conclude a fairly high percentage 
of teachers (considering the answer "No", this is a total of $15 \%$ for the general sample and $30 \%$ for the group of LSB teachers), who, at least, did not consider the possibility of organizing, managing and supporting SRA in their subject.

To the question "Do you have experience in organizing and supporting students' research activities in your subject?" the answer "I do this on a regular basis" was given a little more than $16 \%$ of the respondents; "Occasionally, the work is done" $-46 \%$ of the survey participants; "Only start working in this direction" $-25 \%$ of the respondents; "Do not do this work" $-12 \%$ of those who took part in the survey. For LSB teachers, these indicators were $2 \%, 51 \%, 26 \%$ and $21 \%$, respectively.

Comparing the answers to these two questions gives reason to believe that, on the one hand, teachers recognize the $S R A$ as an important learning process element, but, on the other hand, they engage in this type of activity sporadically, not systematically. Often this work is spot-on, there is ab-work on an individual basis with 2 or 3 students in practice. This assumption is confirmed both by the results of interviews with teachers and by the statistical data analysis on participants in regional competitions of students' research activities: in about $70 \%$ of the SRA supervisors took part in the competition only for certification. Thus, the need to involve all students in the process of research activities in accordance with the requirements of the FSES of Secondary General Education contradicts the level of teachers' readiness to scale this type of activity.

Part of the conclusion about the lack of teachers' systematic work to develop students' research skills, including in the framework of specially organized research activities, is confirmed by the answers to the question "Do you use research teaching methods in the classroom?". Only $25 \%$ of respondents indicated that they use them on a systematic basis, while the majority $(72 \%)$ use them occasionally. In the group of LSB teachers, these indicators were $14 \%$ and $79 \%$, respectively; and $5 \%$ of respondents found them completely unsuitable for the LSB course.

In our opinion, the results indicate the dissonance presence in the teachers' position: considering research activities as an important training element in their subject, teachers showed much less readiness to manage this type of work, as a separate integral process, and to use research methods in the classroom, which are the initial, propaedeutic stage of mastering research activities. Most teachers perceive research activities as independent from everyday learning and are not integrated them into the whole educational process, but "removed" from it, turning into independent teaching element. At the same time, the SRA mandatory provision by all students as part of the final certification is a requirement of the FSES of Secondary General Education. For a teacher, this means that the SRA providing as a separate type of learning and cognitive activity turns into an overtime teaching workload that requires free time. For schoolchildren, along with preparing for the Unified State Exam and other tests, frequently outside of the main school time, it becomes another educational task that also requires additional time.

Using research methods in the classroom on a systematic basis could lay the foundation for future research activities, reduce the time for its organization and preparation, and mitigate the burden on both the teacher and the student. However, such a methodological link is not observed by most of the teachers, while the lack of time and heavy workload as a factor that makes it difficult to manage SRA, both teachers (based on the results of individual interviews) and some researchers remark. For example, [19, 20] point out that as to the Middle School Teachers opinion too much time and energy are involved in SRA, which prevents its implementation in teaching practice.

Thus, one of the main lines of modifying the future LSB teachers' professional training is the skill development that contribute to the effective design and upcoming activities management: the optimal form choice of performing tasks and achieving goals, the systematic vision of the upcoming activities, the ability to build logical chains and sequence 
of actions, time-management, the development of skills for activities coordinating and monitoring. As well, the conscious planning formation, the ability to put forward and maintain activity goals as individual personal characteristics that increase the professional future teachers' competitiveness, is indicated by [21].

According to the respondents' majority, involving students in research activities provides teacher with the opportunity to realize the potential of each student. This answer to the question "In your opinion, the organization of students' research activities gives (can give) you as a teacher an opportunity..." was given by $52 \%$ of the respondents. A slightly smaller number of respondents believe that SRA help teacher to improve the level of students' subject knowledge (43\%), gives teacher the opportunity for professional development $(41 \%)$ and contributes to the requirements implementation of the FSES (38\%). It should be noted that personal motives of moral or material incentives took the last place. For LSB teachers, the ability to learn something new in the subject (35\%) was an additional factor (Fig.1).

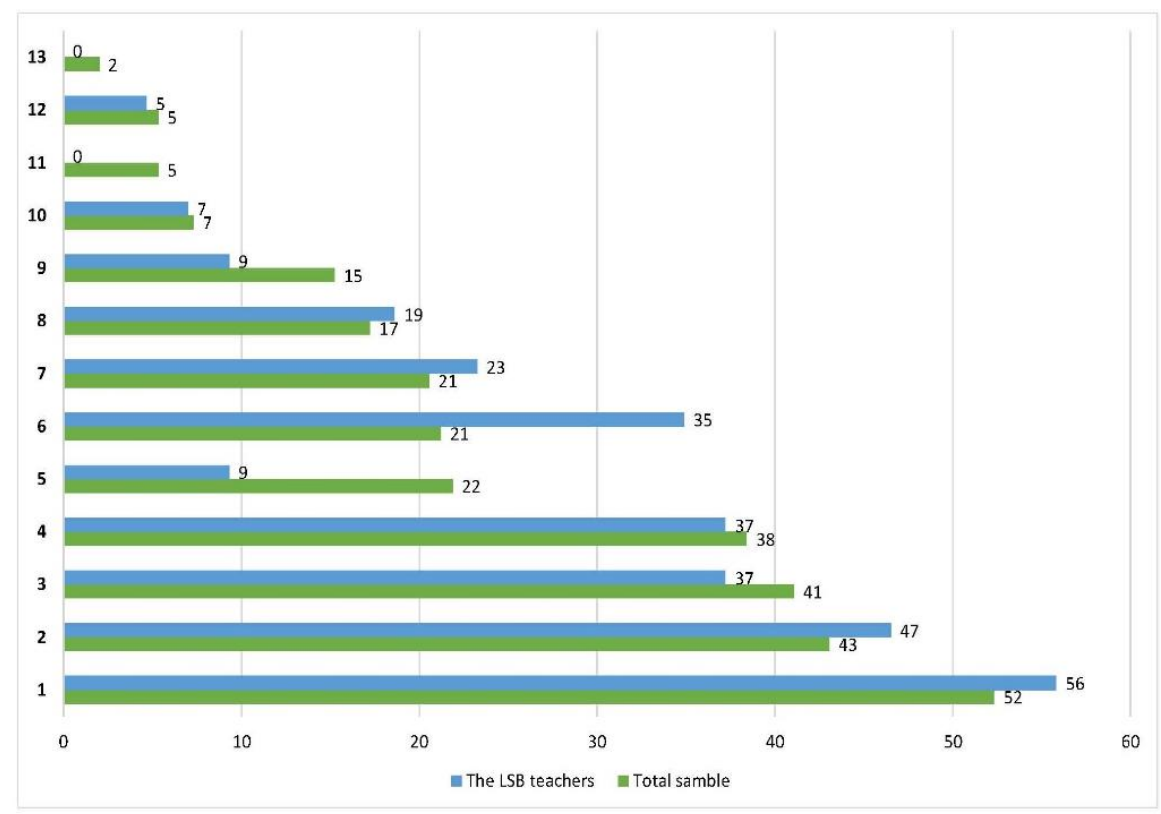

Fig. 1. Distribution of respondents' answers to the question "In your opinion, the organization of students' research activities gives (can give) you as a teacher an opportunity..." (\%), 2020.

Where: 1 - To realize the each student's full potential; 2 - To raise the level of students' subject knowledge; 3 - To develop as professional; 4 - To meet the FSES requirements; 5 to reach personal and professional fulfillment; 6 - To learn something new for the taught subject matter; 7 - To form an universal learning skills, and meta-subject competences of pupils; 8 - To get satisfaction of the work performed; 9 - To build constructive relationships with students; 10 - To obtain moral encouragement; 11 - To obtain professional recognition; 12 - To get financial incentives; 13 - To get social approval.

According to the general respondents' sample as for students' research activities primarily contribute to the research skills development (51\%), critical and analytical thinking development (44\%), students' self-development (38\%), helps to form the ability to work with information sources (37\%) and organize self-education process $(34 \%)$. The data was obtained when analyzing teachers' responses to the question "In your opinion, students' engagement in research activities primarily helps (can help) them to ...". We can see a slightly different distribution for the LSB teachers' sample (Fig. 2). 


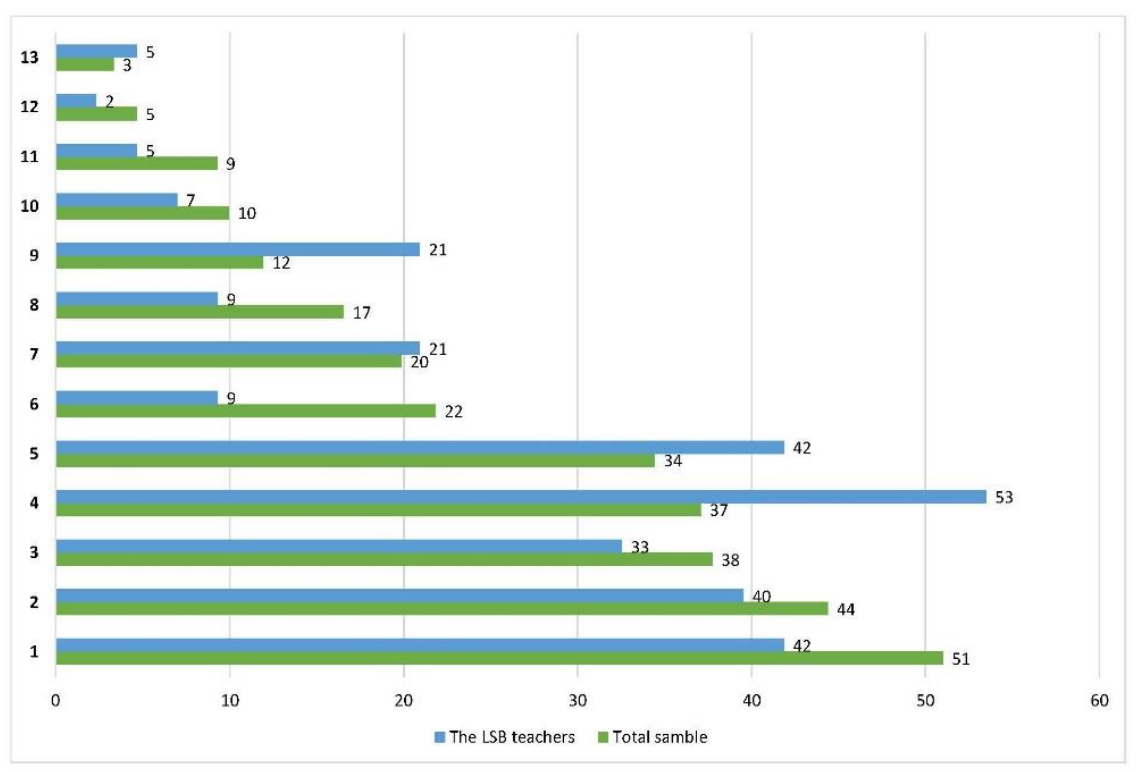

Fig. 2. Distribution of respondents' responses to the question "In your opinion, students' engagement in research activities primarily helps (can help) them to ..." (\%), 2020.

Where: 1 - To develop research skills; 2 - To develop critical and analytical thinking; 3 - To contribute to students' self-development; 4 - To work with information sources; 5 - To manage self-education process; 6 - To orient students professionally; 7 - To form metasubject competencies; 8 - To train for future scientific activities; 9 - To develop communicative universal learning skills; 10 - To develop personal universal learning skills; 11 - To acquire social experience; 12 - To receive material incentives; 13 - To develop regulatory universal learning skills.

Thus, the main research activities advantages for students from the LSB teachers' point of view were its focus on the skills formation to work with information sources $(53 \%)$, manage self-education process (42\%), develop research skills (42\%), critical and analytical thinking (40\%).

Based on the responses, we can say that teachers associate research as a learning technology, first of all, with the students' development, at the same time, perceiving themselves as a participant in this process in the new professional role of the SRA supervisor.

Let's pay attention to the leading position of the ability to work with information sources, which in the group of LSB teachers surpassed even the research skills development. We see the explanation in the fact that working with literature is the most well-developed method used in the study of the LSB course. Most home and optional tasks are reduced to working with additional information sources in order to write messages, essays, memos to the detriment of research tasks [22]. We follow the opinion, that the competent work skills development with information sources is an integral part of the work on the research, helping students to develop skills of analysis, synthesis, generalization, data comparison, highlighting the author's thoughts, searching for contradictions. As [23] point out, working with information is important in two research aspects: forming primary ideas about the subject area and testing hypotheses. As the dominant teaching method in the LSB course, working with literary sources should already form the appropriate skills, however, teachers pass this educational request to another type of activity. This thesis again brings us back to the problem of teachers' skills formation of effective use of time and the lesson potential in the research 
skills development and competencies, as well as the research methods application in teaching practice in general.

\section{Conclusions}

In this study, based on the analyzed responses to questions designed questionnaires, summarizing results of the interviews and group discussions with target group representatives, pedagogical and methodical literature analysis and regulatory documents drafted the idea of reflexive teachers' evaluation attitude in applying the students' research activities in teaching practice and its educational potential, both for the teacher-supervisor and the student.

First, the subject content of the LSB course provides a powerful practice-oriented basis for organizing highly effective personal-oriented students' research activities, the potential of which is not fully realized and, as a result, is not used in the teaching practice of a significant part of teachers.

Secondly, the students' research activities in most cases are not built into the lesson logic, it is perceived by teachers as a separate educational task, managing of which requires additional time and energy. This position hinders the scaling up of research activities as an effective way to develop the school students' skills and competencies that are in demand by the labor market, and indicates the need to improve the teachers' professionalism in the design, planning and rational organization of learning activities based on the research method.

Third, there is a practical need to expand teachers' opportunities understanding, advantages and students' research activities educational potential in the meta-subject competencies' development, universal learning skills, personal characteristics, as well as its psychological and social significance for older adolescents.

Based on the analysis, we can state that there is an urgent need to update not only teacher training programs, but also to monitor professional pedagogical training programs, considering the practical need to form the future Life Safety Basics teacher's functional preparedness to design, manage and support students' research activities on the subject in the classroom and in extracurricular activities as an independent integral process at the high school level.

\section{References}

1. S. Zenkina, E. Gerasimova, Standards and monitoring in education 6(6), 9-12 (2018)DOI: https://doi.org/10.12737/article_5c065b9860b7a5.04060515

2. Ya.N. Ivanova, G.A. Kostetskaya, Proceedings of the IV Interregional Scientific and Practical Conference with International Participation (SakxSU, Yuzhno-Sakxalinsk, 2014)

3. M.A. Kocheva, Yu.V. Gotuleva, S.Yu. Likhacheva, T.V. Yurchenko, Modern problems of science and education 2 (2020) DOI: 10.17513/spno.29684

4. M.M. Novozhilova, Formation of a culture of research activities of high school students in the context of profile training (candidate dissertation) (Moscow Pedagogical State University, Moscow, 2008)

5. O.V. Petunin, Profession-oriented school 7(5), 3-7 DOI: https://doi.org/10.12737/article_5da026d7c9a377.80412392(2019). 
6. V.V. Gafner, Modern education in the field of the Life Safety Basics course: theory, methodology and practice. Materials of the International Scientific and Practical Conference, 55-60 (2018)

7. T.V. Karpacheva, Problems and prospects of education development in Russia 7, 207212 (2011)

8. Yu.B. Blinov, International scientific journal "Innovative science" 11-3, 161-165 (2016)

9. N.M. Chernyavskaya, L.B. Aybazova, T.N. Inglik, Modern problems of science and education 4 (2018)

10. W. DiBiase, J.R. McDonald, Journal of Educational Strategies, Issues and Ideas 88(2), 29-38 (2015) DOI: 10.1080/00098655.2014.987717

11. N.A. Belova, L.V. Kirdyanova, Science and School 5, 76-80 (2017)

12. L.I. Ermakova, G.M. Yanyushkina, Modern problems of science and education 2 (2019)

13. O.V. Muromtseva, Modern problems of science and education 4 (2018) DOI: 10.17513/spno. 27839

14. N.N. Sabel'nikova-Begashvili, S.A. Khudoverdova, Standards and monitoring in education 3, 11-16 (2020) DOI: https://doi.org/10.12737/1998-1740-2020-11-16

15. R.I. Aizman, Bulletin of Novosibirsk State Pedagogical University 5, 9-19 (2014)DOI: $10.15293 / 2226-3365.1405 .01$

16. V.V. Gafner, Monitoring of the Life Safety Basics teacher professional competence development (candidate dissertation) (Ural State Pedagogical University, Yekaterinburg, 2005)

17. M.A. Martins-Loução, G. Gaio-Oliveira, R. Barata, N. Carvalho, Journal of Biological Education (2019) DOI: 10.1080/00219266.2019.1609566

18. National Research Council. Preparing Teachers for Inquiry-Based Teaching. Inquiry and the National Science Education Standards: A Guide for Teaching and Learning (The National Academies Press Washington, DC, 2000) DOI: 10.17226/9596

19. W.P. Baker, M. Lang, A.E. Lawson, A Journal of Educational Strategies, Issues and Ideas 75(5), 248-252 (2002)

20. S. Baroudi, M.R. Helder, Research in Science \& Technological Education (2019) DOI: $10.1080 / 02635143.2019 .1651259$

21. I.V. Lebedeva, N.V. Fomina, Modern problems of science and education 6 (2018)

22. N.V. Avdeeva, The world of science, culture and education 5(30), 11-13 (2011)

23. W.R. Joolingen, Z.C. Zacharia, Technology-Enhanced Learning. Principles and Products (Springer, Berlin, Heidelberg, 2009) 